\title{
artigo
}

Russo, D.S.A.; Machado, M.L.C.A.

Grupo terapêutico de familiares de crianças com alteração de linguagem

\section{Grupo terapêutico de familiares de crianças com alteração de linguagem}

Therapy group for families of children with language disorders

Grupo terapéutico de familias de niños con cambio de idioma

\section{RESUMO}

Objetivo: Apresentar a proposta de grupo terapêutico de familiares de crianças com alterações de linguagem a partir da análise de relatos sobre as mudanças ocorridas na relação com a criança. Métodos: Estudo de caso de um grupo de familiares de crianças encaminhadas para atendimento fonoaudiológico com queixa de não falar ou falar pouco. A partir da análise microgenética (em concordância com a abordagem histórico-cultural) de recortes de episódios vivenciados no grupo terapêutico, são discutidas as representações discursivas das mães sobre o desenvolvimento infantil e a participação do outro nesse processo. Resultados: 0 discurso materno apresenta mudanças do comportamento comunicativo entre a criança e o familiar. Surge também a percepção das mães sobre a relação existente entre a intervenção do adulto como parceiro da criança na brincadeira e o desenvolvimento linguístico infantil. Conclusão: 0 estudo é relevante tanto por sua possibilidade de mostrar a efetividade de outras formas de atuação nos quadros de transtornos de linguagem, envolvendo efetivamente a figura familiar; quanto por tratar-se de uma proposta transdisciplinar em Saúde Coletiva, posicionando o fonoaudiólogo como mediador do grupo terapêutico. DESCRITORES: Linguagem; Terapia Fonoaudiológica; Relações Familiares.

\section{ABSTRACT}

Objective: To present the proposition of a therapeutic group of children with speech disorders family members, based on the analysis of reports about the changes noticed in their relationship with the child. Methods: A case study was carried out, based on a group of family members of children with a referral to speech therapy due to a complaint on no or truly little speech skills. Starting from a microgenetic analysis (in accordance with the historical-cultural approach) of clinical episodes clippings, experimented within the therapeutic group, mothers' discursive representations on child development and the participation of the other in this process have been discussed. Results: Mothers' speech show up the communicative behavior changes between child and family members. Besides, it highlights their perception on the relation between the intervention of an adult as a partner in child games and the child linguistic development. Conclusion: This study is important both for the possibility of showing the effectiveness of different ways to approach language disorders, with a real involvement of the family, and for its proposition of a transdisciplinary approach on Collective Health, placing the phonoaudiologist as the facilitator of the therapeutic group.

DESCRIPTORS: Language; Speech Therapy; Family Relations.

\section{RESUMEN}

Objetivo: Presentar el grupo terapéutico propuesto de familiares de niños con trastornos del lenguaje basado en el análisis de informes sobre los cambios que ocurrieron en la relación con el niño. Métodos: Estudio de caso de un grupo de familiares de niños referidos a terapia del habla con quejas de no hablar o no hablar mucho. A partir del análisis microgenético (de acuerdo con el enfoque histórico-cultural) de recortes de episodios experimentados en el grupo terapéutico, se discuten las representaciones discursivas de las madres sobre el desarrollo del niño y la participación del otro en este proceso. Resultados: El discurso materno presenta cambios en el comportamiento comunicativo entre el niño y el pariente. También surge la percepción de las madres sobre la relación entre la intervención del adulto como compañero del juego y el desarrollo lingüístico de los niños. Conclusión: El estudio es relevante tanto por su posibilidad de mostrar la efectividad de otras formas de desempeño en el marco de los trastornos del lenguaje, involucrando efectivamente la figura familiar; y porque es una propuesta transdisciplinaria en salud colectiva, posicionando al logopeda como mediador del grupo terapéutico.

DESCRIPTORES: Lenguaje; Terapia del Habla; Relaciones Familiares.

RECEBIDO EM: 14/02/2020 APROVADO EM: 14/02/2020

\section{Daniela Schuewk de Aguiar Russo}

Fonoaudióloga. Mestrado em Saúde Materno-Infantil. Especialização em Audiologia Clínica. Fonoaudióloga do Hospital Universitário Clementino Fraga Filho. RJ/Brasil. https://orcid.org/0000-0002-3747-810X 


\section{Maria Letícia Cautela de Almeida Machado}

Fonoaudióloga. Doutorado em Educação. Mestrado em Distúrbios da Comunicação. Especialização em Linguagem e em Voz. Professora Adjunta da Universidade Estadual do Rio de Janeiro. RJ/Brasil. https://orcid.org/0000-0002-9500-1625

\section{INTRODUÇÃO}

A pós 30 anos da criação do Sistema Único de Saúde (SUS), ainda são encontradas grandes lacunas nos modelos de atenção e gestão dos serviços no que se refere ao acesso e ao modo como o usuário é acolhido nas unidades de saúde pública ${ }^{(1)}$.

$\mathrm{O}$ acolhimento como ato ou efeito de acolher expressa a ideia de aproximação e, por isso, é um dos dispositivos-chave para a efetivação do SUS. Nesse panorama, caracteriza-se como uma das diretrizes de maior relevância da Política Nacional de Humanização do SUS e deve ser entendido como uma orientação dos modos de produção de saúde, assim como uma ferramenta de intervenção na qualificação de escuta, construção de vínculo, garantia do acesso com responsabilização e resolutividade nos serviços. Como ação técnico-assistencial, o acolhimento possibilita a análise do processo de trabalho em saúde com foco nas relações e pressupóe como uma das mudanças a relação entre profissional/ usuário e sua rede social, o que leva ao reconhecimento do usuário como sujeito e participante ativo no processo de produção de saúde ${ }^{(1)}$.

A experiência clínica em Fonoaudiologia obtida em um serviço do SUS mostrou lacunas (como aquelas já mencionadas) que motivaram a realização do presente estudo. Observou-se que boa parte dos inscritos na fila de espera para o atendimento fonoaudiológico no serviço eram crianças que não falavam ou falavam pouco, e que não tinham questões em outras áreas do desenvolvimento. Além disso, aos responsáveis por crianças abaixo de três anos de idade que buscavam a fonoterapia com a queixa de não falar ou falar pouco, a orientação dada era inseri-las em creches ou ambientes escolares com o objetivo de promover o desenvolvimento de fala/linguagem. Se, aos completos três anos de idade a criança ainda apresentasse sinais de alteraçốes nesse processo, só então, o responsável deveria retornar ao serviço de Fonoaudiologia para que se realizasse o acompanhamento profissional.

Diante desse cenário de demanda não absorvida pelo serviço, é importante lembrar de que o processo de apropriação da linguagem da criança diz muito sobre o desenvolvimento infantil. Por isso, quando se verifica que aos 18 meses a criança não fala ou fala pouco, enquanto autores ${ }^{(2)}$ apontam que, em média, nesta faixa etária os infantes costumam emitir frases de 2 palavras, essa observação sinaliza que algo pode estar interferindo negativamente no desenvolvimento da criança. Nesse sentido, entende-se que um atraso nas primeiras etapas do desenvolvimento linguístico pode trazer implicações às aprendizagens subsequentes, inclusive, no processo de leitura e escrita. Como afirma Mousinho(3), as modalidades oral e escrita da linguagem formam um continuum, pois "a LINGUAGEM é uma só".

Valendo-se da teoria histórico-cultural proposta por Vygotsky, a qual defende que o indivíduo desenvolve-se e aprende na interação social ${ }^{(4)}$, e de que os pais proporcionam o ambiente em que a criança passa a maior parte do tempo ${ }^{(5)}$, considerar a participação familiar como elemento essencial no desenvolvimento da linguagem infantil é fundamental.

A respeito da necessidade de agilizar o atendimento e diminuir a fila de espera, Santos ${ }^{(6)}$, Correa $^{(7)}$ e Machado ${ }^{(8)}$ comentam que, desde a década de 1980, os profissionais diante da realidade de uma grande demanda para o atendimento nos serviços de saúde pública, sem a possibilidade de oferecer a todos a assistência individual, passaram a optar pelo grupo terapêutico fonoaudiológico. De acordo com Morei$\mathrm{ra}^{(9)}$, a discussão em grupo é uma estratégia de saúde coletiva, de promoção da saúde, pois tem como objetivo maximizar o potencial dos sujeitos por meio de um olhar mais abrangente para o desenvolvimento humano. $\mathrm{O}$ autor $^{(9)}$ ainda propõe que a abordagem com grupos de mães e pais pode ser produtiva, por exemplo, durante o período em que as crianças aguardam por atendimento nos serviços públicos, pois isso pode minimizar ou até resolver o comprometimento de linguagem da criança, além de ter efeito na diminuição da fila de espera para o atendimento fonoaudiológico. Dessa forma, os próprios familiares poderão participar ativamente do processo terapêutico e da evolução do desenvolvimento infantil.

Diante desse contexto, o objetivo desse trabalho é apresentar uma abordagem terapêutica com um grupo de familiares de crianças com alterações de linguagem a partir da análise dos relatos dos mesmos sobre as mudanças ocorridas na relação com a criança, expostos na discussão grupal.

\section{METODOLOGIA}

O presente estudo foi aprovado pelo Comitê de Ética em Pesquisa da Universidade Federal Fluminense sob o número CEP-UFF5243/2014 (CAAE: 14552813.1.0000.5243).

Pesquisa de análise qualitativa, cujo material do estudo de caso foi coletado de uma abordagem desenvolvida com um grupo de familiares de crianças com queixa de não falar ou falar pouco. Tal intervenção foi realizada no Ambulatório do Desenvolvimento do Hospital Infantil Ismélia da Silveira, no Município de Duque de Caxias/RJ, no ano de 2014.

Critérios de seleção dos sujeitos da pesquisa: foram selecionados 10 familiares de 10 crianças com idade entre 21-51 meses, inscritas na fila de espera para o atendimento fonoaudiológico no Ambulatório com a queixa de não falar ou falar pouco. Foram excluídos os familiares de crianças com deficiência (visual, auditiva ou intelectual) e/ou transtorno do espectro autista inscritas na fila de espera para a fonoterapia no Ambulatório, pois essas condições apresentam especificidades 
quanto à sintomatologia e demandas de atendimento.

Cabe frisar que antes de serem inscritas na fila de espera para a fonoterapia, essas crianças haviam sido submetidas à triagem fonoaudiológica e encaminhadas para a avaliação com a Pediatra do Desenvolvimento do mesmo Hospital, como também para exames audiológicos e oftalmológicos.

Antes da intervenção grupal, familiares e crianças foram convocados para a realização de: anamnese; filmagem da brincadeira entre responsável e criança; orientação sobre a abordagem terapêutica grupal; e obtenção de assinatura do TCLE (Termo de Consentimento Livre e Esclarecido).

A título de esclarecimento sobre a abordagem terapêutica escolhida, foi informado aos familiares como ela se daria. Assim, comunicou-se que a proposta compreendia um número limitado de nove encontros, na frequência de uma vez por semana, transcorridos em torno de 3 meses, com a duração média de duas horas cada sessão. Além disso, apresentou-se aos mesmos os objetivos da atividade, a saber: refletir sobre o desenvolvimento das crianças, compartilhar experiências relacionadas a isso e discutir estratégias facilitadoras da estimulação da aprendizagem linguística infantil.

Após a apresentação da abordagem aos familiares, foi solicitada a assinatura do TCLE dos sujeitos responsáveis pelos menores com queixa de não falar ou falar pouco envolvidos nesse trabalho como comprovação do aceite de participação na pesquisa para que, então, fossem realizados os demais procedimentos.

A anamnese deu-se de forma semi-dirigida, com o objetivo de coletar informações sobre o desenvolvimento global da criança, com destaque para as questões relativas à comunicação e linguagem. $\mathrm{Na}$ ocasião, também foi possível verificar se a queixa principal de não falar ou falar pouco, informada no momento da inscrição da criança na fila de espera, ainda procedia no momento da convocação da família pelo serviço.

$\mathrm{Na}$ filmagem da brincadeira entre familiar e criança, o interesse era registrar a dinâmica interacional do par, a qualidade das trocas comunicativas. Isso representou uma forma de observação da performance comunicativa das crianças e dos pais. O registro de vídeo-gravação foi feito com a filmadora marca SONYHMX-F80 e iniciou-se após a preparação do ambiente com a disposição de elementos lúdicos sugestivos de brincadeiras motoras, gráficas, de imitação de cenas vivenciadas e de faz-de-conta. O incentivo à realização desses tipos de brincadeira considerou suas etapas de evolução e seu paralelismo com as fases do desenvolvimento linguístico. Na ocasião, orientou-se aos familiares que os mesmos brincassem livremente com as crianças, da forma mais próxima possível ao modo como costumam fazer em casa. Foi informado também que o filme conteria dez minutos dessa brincadeira.

Com relação ao material do estudo, a intenção era coletar dados obtidos no atendimento de um grupo de familiares, no entanto, só foi possível a participação das mães das crianças, pois alguns dos familiares convocados apresentaram critério de exclusão ou retiraram-se da pesquisa durante a realização das avaliações. Além disso, foi permitido e incentivado que as mães levassem para a grupoterapia qualquer outro familiar com esse interesse, no entanto, não houve adesão de outro representante da família. Dessa forma, a coleta de material foi realizada a partir do atendimento de um grupo de mães de crianças encaminhadas para atendimento fonoaudiológico com queixa de não falar ou falar pouco.

Para compor o grupo, havia, primeiramente, cinco representantes de núcleos familiares, mães apenas. Num segundo momento, ocorreu a ideia de inserir no grupo alguém com quem as mães se identificassem e que pudesse atuar no papel de mediador das aprendizagens promovidas entre o grupo e a terapeuta (uma das autoras dessa pesquisa). Nesse caso, pensou-se em alguém que pudesse contribuir com a experiência obtida em situação semelhante a das mães que compõem o presente grupo terapêutico. Para isso, foi convidada a mãe de uma criança com diagnóstico anterior de atraso simples de linguagem que teve a experiência prévia desse mesmo modelo de intervenção grupal oferecido pelo referido Serviço de Fonoaudiologia.

De forma a garantir a filmagem das reuniões em grupo, foi convidada a mãe de uma criança autista, acompanhada no mesmo Serviço, para assumir essa atividade, uma vez que a mesma encontrava-se disponível para realizar tal função por estar sempre presente na Unidade no horário de funcionamento do grupo. No entanto, no decorrer das dinâmicas grupais, essa mãe passou a envolver-se nas discussões e, após a tentativa bem-sucedida de posicionar a câmera de modo a compreender todos os participantes em seu campo visual, a responsável passou a integrar ativamente o grupo de mães, com o qual ela se identificou e no qual foi acolhida.

Cabe acrescentar que essas duas mães também assinaram o TCLE e que o fato de terem entrado na dinâmica grupal não mudou a proposta inicial em sua estrutura. Por fim, a composição do grupo terapêutico propriamente dito contou com a presença de um total de sete mães e a terapeuta.

Escolheu-se fazer referência às mães participantes, ao longo do trabalho, utilizando as iniciais do nome e do último sobrenome em letra maiúscula: MP, MR, VO, ES, DS, NJ e SM. Já a terapeuta, teve sua identificação composta pela letra " $T$ ” junto à letra inicial de seu próprio nome (D-T).

O planejamento das sessões foi elaborado com base na concepção histórico-cultural ${ }^{(10,11)}$, bem como na perspectiva de grupo, definida como possibilidade de interlocuções, identificações, representações, continência e construção coletiva de significações ${ }^{(8)}$. Para tanto, considerou-se, também, a proposta Hanen, a qual tem como objetivo no programa It takes two to talk promover a formação de mães e pais, a intervenção precoce na linguagem infantil e o suporte social familiar ${ }^{(12)}$.

No espaço do grupo, discutiram-se: como e por que as crianças comunicam-se; os níveis de desenvolvimento linguístico; resultados obtidos com atitudes de esperar, escutar e observar a criança; es- 
tratégias facilitadoras da comunicação; dinâmica conversacional; uso da rotina para incentivar e mediar a apropriação da linguagem; importância da brincadeira e como potencializá-la; além do uso de recursos como livros, artes e músicas. Também foram incluídas a observação e a discussão dos vídeos da brincadeira entre adulto e criança, assim como a retomada de questões tratadas nos momentos em que houve demanda, entre outras atividades e temas de interesse.

A coleta de dados foi realizada mediante vídeo-gravações das sessões terapêuticas grupais, as quais foram transcritas ortograficamente conforme às normas de Marcuschi $^{(13)}$. Os sinais utilizados na pesquisa indicam: [[ - falas simultâneas no início do turno; [ - concomitância de falas que não se deu desde o início do turno; (( )) - comentários do analista; ... - transcrição de apenas um trecho (uso de reticências no início e no final da transcrição); /.../ - corte na produção de alguém.

$\mathrm{Da}$ transcrição, foram selecionados recortes da dinâmica grupal que possibilitassem a análise proposta no objetivo desta pesquisa. Para a apreciação qualitativa dos mesmos, foram adotadas as diretrizes da análise microgenética, a qual elege episódios típicos ou atípicos que permitem interpretar o fenômeno de interesse por meio de indícios de aspectos relevantes de um processo em curso $^{(14)}$, bem como a concepção histórico-cultural ${ }^{(10,11)}$.

Assim, fizeram parte do material de análise: os mencionados recortes; as observações da terapeuta a respeito dos familiares e da brincadeira de cada díade; além das informações colhidas na anamnese.

\section{RESULTADOS E DISCUSSÃO}

A idade média das mães participantes do grupo terapêutico foi de 35,6 anos. Quanto ao nível de escolaridade apresentado pelas responsáveis, os resultados mostraram que o percentual de $28,57 \%$ foi o mesmo para aquelas com EFC, EMI e EMC, e que $14,28 \%$ das mães tinham ESI. Das atividades laborais, $42,86 \%$ das figuras maternas estavam inseridas na área de cor- te/costura; $28,57 \%$ eram do lar; e $28,57 \%$ tinham outro tipo de ocupação. O número médio de filhos era de 1,86. A idade média das crianças com alteração de linguagem pertencentes ao estudo foi de 35,7 meses. Além disso, $100 \%$ das crianças com alteração de linguagem dessa pesquisa eram do sexo masculino. Os dados demográficos maternos e do filho participante do estudo supracitados são apresentados na Tabela 1.

A seguir, a apresentação e análise da transcrição de 6 recortes de episódios selecionados como objeto de discussão com o destaque em negrito para as partes enunciativas de maior valor semântico.

\section{Interlocução 1}

D-T: Você teve alguma dúvida essa semana? Teve alguma diferença com seu filho? MP: Não, não. Agora, ele tá indo. Já tá indo já ao banheiro sozinho.

D-T: Ih, que legal! Que bacana!

MP: É, agora ele já tá indo já. Aí, fala: “mãe, eu quero fazer cocô". Aí, vai lá e fica lá. "Aí, quando você acabar, você me chama”. Aí, ele quando acaba, ele me chama. Ele, agora, tá assim. Não tá fazendo mais na fralda, graças a Deus.

Tabela 1. Dados demográficos maternos e do filho participante do estudo. Rio de Janeiro, RJ, Brasil, 2014

\section{Mãe}

\begin{tabular}{|c|c|c|c|c|c|c|}
\hline \multirow[b]{2}{*}{ Identificação } & \multirow[b]{2}{*}{ Idade } & \multicolumn{2}{|l|}{ Mãe } & \multirow[b]{2}{*}{$\begin{array}{l}\text { Número de } \\
\text { filhos }\end{array}$} & \multicolumn{2}{|c|}{ Criança } \\
\hline & & Escolaridade & Profissão & & Idade & Sexo \\
\hline MP & 40 & EFC & Corte/costura & 2 & $\begin{array}{l}2 \text { anos e } \\
9 \text { meses }\end{array}$ & M \\
\hline MR & 32 & EMI & $\begin{array}{l}\text { Analista de } \\
\text { transporte }\end{array}$ & 2 & 3 anos & $\mathrm{M}$ \\
\hline VO & 33 & EMI & Corte/costura & 4 & $\begin{array}{c}1 \text { ano e } \\
10 \text { meses }\end{array}$ & M \\
\hline ES & 34 & ESI & $\begin{array}{l}\text { Recepcio- } \\
\text { nista }\end{array}$ & 1 & $\begin{array}{l}2 \text { anose } \\
4 \text { meses }\end{array}$ & M \\
\hline DS & 37 & EMC & Dolar & 1 & $\begin{array}{l}2 \text { anose } \\
2 \text { meses }\end{array}$ & M \\
\hline SM & 31 & EMC & Dolar & 1 & $\begin{array}{l}4 \text { anose } \\
6 \text { meses }\end{array}$ & M \\
\hline NJ & 42 & EFC & $\begin{array}{c}\text { Costura (Au- } \\
\text { tônoma) }\end{array}$ & 2 & $\begin{array}{l}4 \text { anos e } \\
3 \text { meses }\end{array}$ & M \\
\hline
\end{tabular}

Nota: EFC - Ensino Fundamental Completo; EMI - Ensino Médio Incompleto; EMC - Ensino Médio Completo; ESI - Ensino Superior Incompleto.
Uma das queixas sinalizadas pela mãe MP na anamnese era com relação ao filho não saber pedir para ir ao banheiro, inclusive, esse era o motivo pelo qual a criança ainda não estava inserida em ambiente escolar. No relato materno, havia a preocupação com a dificuldade do filho em comunicar o desejo de ir ao banheiro, acreditando que a escola poderia não ficar atenta $\mathrm{a}$ isso $\mathrm{e}$ deixá-lo sujo. Embora essa queixa estivesse relacionada à independência do filho (ir ao banheiro), a mesma estava vinculada à performance comunicativa do menor.

$\mathrm{Na}$ análise feita pela terapeuta da vídeo-gravação da brincadeira entre o adulto e a criança, foi observado um comportamento ansioso e diretivo de MP, indicando que a responsável não oferecia oportunidades para o filho ter mais autonomia. $\mathrm{Na}$ ocasião, pôde-se perceber também uma conduta materna de "professora". A respeito da descrição dos tipos de pais feita pelo método Hanen, o perfil "professor" é aquele que nunca brinca com seu filho, mas que não perde uma ocasião para ensinar tudo a ele ${ }^{(5)}$.

No grupo terapêutico, tais perfis foram discutidos, bem como sinalizada a necessidade de escuta como forma 
de estar atento às intenções comunicativas dos filhos e de abrir caminho para o diálogo. Ao segundo encontro grupal, a mãe declarou o fato de ele já estar indo ao banheiro sozinho como uma mudança do comportamento infantil e da relação familiar.

Comparando-se a queixa materna inicial, do filho não saber pedir para ir ao banheiro, com a fala do mesmo "Mãe, eu quero fazer cocô", reproduzida pela mãe, vê-se a substituição da falta de atitudes comunicativas que informassem a necessidade fisiológica pela comunicação verbal supracitada. Isso significa que antes da enunciação ora apresentada, não eram observadas a intenção de compartilhar com o outro sobre o desconforto e a solicitação de auxílio dirigida à mãe.

A responsável pôde relatar mais uma vez essa diferença relacional quando ela se colocou disponível para ajudar ao filho e recebeu um feedback positivo disso, como aparece no trecho: "Aí, quando você acabar, você me chama”. "Aí, ele quando ele acaba, ele me chama”. Isso evidencia o estreitamento da relação da díade mãe-criança e mostra o quão afinada deu-se essa troca dialógica, com uma resposta imediata e favorável à expectativa.

Baseando-se no enunciado "Ele, agora, tá assim”, também fica evidente a percepção materna da mudança das atitudes de comunicação do filho e, consequentemente, da díade. Acredita-se que tal avanço na linguagem da criança e em suas relações foi possível mediante à observação da mãe de seu próprio comportamento, conforme sua participação no grupo.

Ao promover novas relações interpessoais, o grupo torna os indivíduos receptivos a diferentes experiências, conhecimentos e possibilidades de pensar e agir nas relações ${ }^{(8)}$. De forma a sustentar a prática grupal com mães de crianças com distúrbios de linguagem, em um estudo ${ }^{(15)}$, também concluiu-se que houve empoderamento da função materna, o que permitiu que as mães entendessem melhor o próprio papel no desenvolvimento infantil.

\section{Interlocução 2}

D-T: /.../ MR falou que tinha algumas novidades pra contar e tal. E eu sempre gosto de saber de novidades.

MR: Então, mamãe, papai, até então, era só mãe, pai. Mamãe, papai. Eu pergunto pra ele o que é isso aqui ((aponta para o olho)) e ele já fala olho, entendeu? Boca, orelha, tanto que eu tava ali sentada com ele e tava perguntando tudo de novo. Aí, ele falou tudo direitinho: dente. Só que assim, ainda não sai "dente", den, den, entendeu? E a professora falou que ele já tá, ela pergunta da galinha pintadinha pra eles, aí, ele já fala. Ela ajudando, ele já fala: "é tia". Aí, acho que ele chamava ela de tia "Di". Aí, já chama ela de tia "Didi", entendeu? Então, assim, já tá saindo do, eu acho que agora assim, algumas coisas ele ainda prende a língua até ele começar a falar. Mas, assim, a gente tá ajudando, meu marido também, entendeu? Deixa ele falar quando ele quer conversar com alguma coisa. Mas, aí, ele pede pra explicar, aí, ele fica, pra explicar da forma dele, né? Aí, a gente entende às vezes. Às vezes, a gente não entende. Mas, assim, ele tá bem saído bastante. Já tá vendo, entendeu? Pra conversar, já senta pra conversar. Ele mudou bastante.

À época da entrevista, a responsável MR mencionou que seu filho apontava muito; vocalizava pouquíssimo; e falava apenas parte (sílaba, talvez) de algumas palavras, a qual nem sempre era produzida sonoramente semelhante à palavra supostamente pretendida.

$\mathrm{Na}$ análise do momento lúdico entre o adulto e a criança, foi observado um comportamento ansioso e crítico da mãe, além de condutas do tipo pai "salvador" e "professor" de acordo com o método Hanen. Para Machado ${ }^{(5)}$, o pai "salvador" é quem sempre quer fazer tudo por seu filho, sem dar-lhe a oportunidade de desenvolver habili- dades e personalidade própria. Dessa forma, demonstrou dissociar sua participação da performance comunicativa infantil. Sendo assim, não havia valorização materna suficiente das tentativas comunicativas do menor, de forma a restringir o desenvolvimento de linguagem do mesmo.

Os pais, potencialmente, são bons observadores do desenvolvimento da fala das crianças e fundamentais para sua estimulação ${ }^{(16)}$, já que, normalmente, compõem o ambiente onde a criança passa a maior parte do tempo.

Nesse sentido, a partir da integração dessa mãe ao grupo terapêutico, em seu discurso, a mesma relaciona a produção oral de palavras de maior número silábico e de novo vocabulário com o desenvolvimento da linguagem de seu filho: "Então, mamãe, papai, até então, era só mãe, pai”; "Ainda não sai "dente","den","den", entendeu?".

Quando a mãe comenta: "Algumas coisas ele ainda prende a língua até ele começar a falar, mas, assim, a gente tá ajudando, meu marido também", ela valoriza a participação do adulto, sobretudo a dos pais na construção da linguagem da criança. E, por essa razão, na sequência de seu discurso, relata a mudança percebida no desempenho comunicativo do menor, na qualidade da interação social com seus pares "Pra conversar, já senta pra conversar. Ele mudou bastante".

Frente ao exposto, numa perspectiva histórico-cultural, entende-se que é pela atividade dialógica entre a criança e o "outro", quem já desenvolveu um sistema de significação, que a cognição e a linguagem são construídos no infante ${ }^{(17)}$. A autora ${ }^{(17)}$ acrescenta que a linguagem, enquanto procedimento comunicativo, tem um papel de ação sobre o "outro" na interação social; e como procedimento cognitivo, possui um papel de constituição do conhecimento de mundo da criança. 
VO: /.../ ele tá soltando algumas coisas. $\mathrm{D}-\mathrm{T}$ : Mais você acha que ele está soltando porque?

VO: Ah, eu tô brincando com ele.

$\mathrm{Na}$ anamnese, a mãe VO relatou que seu filho ficava mais apontando. Percebia que ele queria falar, mas não conseguia.

$\mathrm{Na}$ análise da brincadeira entre mãe e filho, observou-se inicialmente conduta materna mais ansiosa e diretiva, sendo oferecidas poucas oportunidades de comunicação para a criança. Também foram identificadas atitudes de pai "salvador"(5) na responsável.

A orientação no Programa Hanen é que os pais devem Observar, Esperar e Escutar ${ }^{(12)}$. Ao fazer isso, os pais estão mostrando à criança o quanto de sua própria atenção está sendo dedicada a ela, dada a importância do que tem para comunicar; como também, o momento em que o infante deve apropriar-se de seu turno dialógico, já que se trata de uma troca, na qual os interlocutores alternam-se ${ }^{(18)}$. Tais aspectos foram tratados no grupo terapêutico, o que permitiu a mudança no padrão comunicativo do adulto e da criança. A percepção materna dessa mudança infantil foi evidenciada no comentário: "ele tá soltando algumas coisas”. A responsável relaciona o aparecimento de produçôes orais da criança (conforme a intervenção terapêutica "Mais você acha que ele está soltando porque?”) à troca dialógica entre mãe e filho numa situação lúdica ("Ah, eu to brincando com ele").

As relações estabelecidas entre os sujeitos nos diferentes contextos sociais podem ser entendidas como o espaço em que o processo de desenvolvimento acontece, afetando todos os envolvidos ${ }^{(4)}$. Conforme Mogford e Bishop ${ }^{(19)}$, há evidências de que o adulto e a criança fazem mudanças na estratégia de conversação à medida que a mesma se desenvolve.

\section{Interlocução 4}

ES: Eu tinha dificuldade. Eu vou te ser sincera. A senhora sabe que eu não sou de mentir. Tem tanto trabalho aqui e criança o dia todo chorando no meu ouvido, e quando eu chegava em casa, não tinha paciência de brincar. É, eu olhei no armário. Tinha a massinha que tem um ano. A caixa de massinha que tem 1 ano, mas eu nunca sentei pra brincar com ele. E ele, naquele dia, eu vi que eu tinha que ter um tempo pra brincar com ele. E aí, eu peguei a massinha. Pode ver hoje, ele quer a massinha. Ele quer brincar com a massinha. E lá, e tava 1 ano lá, a massinha lá e eu não tinha aquele tempo de sentar, seja $10 \mathrm{ou}$ 20 minutos. Eu achava que eu não tinha que sentar pra brincar. Sentei, peguei aquela massinha que já estava guardada há maior tempão e vi a necessidade de sentar pra brincar com ele. E ele se sentiu mais à vontade pra sentar. Brincou comigo com a massinha. O pai chegou na hora. Botei o pai pra sentar, pra brincar com ele, que eu tinha que fazer a janta. $O$ pai sentou e brincou com ele. Eu acho que eu não tinha aquele, mesmo 10 ou 20 minutos, que seja pra sentar com ele, eu não tinha. E hoje, eu separo aquele minutinho pra sentar com ele.

Sob entrevista, a mãe ES relatou as seguintes queixas com relação à produção de fala do menor: "Não forma frases. Ainda usa o apontar no lugar da fala. Não entendo o que ele fala, apenas nome das pessoas."

Quando avaliada a relação mãe/filho na brincadeira, viu-se atitude materna ansiosa, diretiva e até controladora, o que gerou um "ambiente" conflitivo e estressante para a criança. Nesse sentido, foram observadas condutas de pai "salvador" e de "professor"(5).

No grupo, a partir da qualidade das relações formadas em seu interior, é possível que os sujeitos se reconheçam no/pelo outro e, assim, compreendam melhor tanto suas próprias dificuldades como as do outro, permitindo que elas sejam ressignificadas ${ }^{(8)}$.

A participação da mãe no grupo deu-se através do relato de suas dificuldades ("Eu tinha dificuldade", "não tinha paciência de brincar"); de seu entendimento da necessidade de mudança das atitudes das figuras materna e paterna com o filho ("naquele dia, eu vi que eu tinha que ter um tempo pra brincar com ele", "Eu achava que eu não tinha que sentar pra brincar", "Botei o pai pra sentar, pra brincar com ele"); além dos resultados obtidos com a transformação da relação familiar-criança ("E ele se sentiu mais à vontade pra sentar", "Brincou comigo", "O pai sentou e brincou com ele", "E hoje, eu separo aquele minutinho pra sentar com ele").

Nos trechos supracitados, a mãe relaciona diretamente o desenvolvimento linguístico infantil ao "brincar" da criança, observando numa releitura do contexto a figura do adulto como mediador da atividade. Dessa forma, ela ocupa seu papel de participação do desenvolvimento linguístico do filho e convoca o pai a fazer o mesmo.

Para o aproveitamento de ocasióes oportunas para a promoção e mediação da linguagem do filho, é necessário que, antes, os pais aprendam a avaliar seu próprio comportamento e percebam as reações da criança ${ }^{(5)}$.

Wiethan, Souza e Klinger ${ }^{(15)}$ destacam a importância da troca dialógica na construção da linguagem e das interpretações feitas acerca das atitudes comunicativas da criança para que as mães compreendam como são fundamentais para o desenvolvimento de seus filhos.

\section{Interlocução 5}

DS: Vai brincar lá, vai brincar lá. Aí, aí, agora, "vamos brincar, vamos brincar". Aí, às vezes, eu desligo até a televisão. Vou lá, desligo a televisão. "Tá, vamos brincar, vamos brincar. Já trago o brinquedo". Jogo tudo na sala. Bagunço a casa.

D-T: Ótimo!

DS: Às vezes, até quando a gente vai terminar a brincadeira, ele até, "não mamãe, não mamãe, senta, senta”.

A queixa materna de DS estava relacionada à dificuldade do filho em expressar-se. DS afirmou que quando o filho queria explicar alguma coisa, fazia sons e gestos e, ainda assim, a mesma não o entendia. 


\section{artigo}

Russo, D.S.A.; Machado, M.L.C.A.;

Grupo terapêutico de familiares de crianças com alteração de linguagem

Sob análise, a brincadeira da díade mostrou atitudes maternas diretivas e do tipo "professora" ${ }^{(5)}$.

A respeito do programa Hanen, a linguagem do ser humano desenvolve-se no ambiente familiar, em meio a estímulos contínuos e necessidades do dia a dia ${ }^{(5)}$. A autora ${ }^{(5)}$ acrescenta que é importante que os pais aprendam a aproveitar, ao máximo, as situações do dia a dia de forma que se tornem uma fonte prazerosa e constante de promoção e mediação da linguagem infantil.

De modo a apresentar a diferença que houve na relação com o filho, a responsável cita que agora o convida para brincarem juntos, chegando a eliminar possíveis distratores para garantir um momento de interação somente entre os dois ('Aí, aí, agora "vamos brincar, vamos brincar", "Aí, às vezes, eu desligo até a televisão"). Como resposta a esse novo comportamento materno de interesse e procura do parceiro infantil para a brincadeira, a criança também se propõe, naturalmente, a estabelecer uma nova forma de relacionamento com sua mãe, comunicando melhor o desejo de tê-la junto ('Às vezes, até quando a gente vai terminar a brincadeira, ele até, "não mamãe, não mamãe, senta, senta”).

\section{Interlocução 6}

DS: É, até eles saíram, hein, NJ? Até ele sair, que ele ((pai)) não saía com o fillho, ele tá passando a sair.

D-T: Ah, gente!

DS: "Vamos ali com o papai, que não sei o quê" ((mãe reproduz o que o pai fala para seu filho)). Ele tá chamando assim. Na verdade, você já vê diferença.

Como produto de uma relação mais afinada entre mãe e filho, já observada na interlocução 5 , obteve-se também na interlocução 6 , um comportamento comunicativo infantil mais interativo e, com isso, a construção de um novo modo de interação, nessa, entre pai e filho.
A mudança na performance interativa/comunicativa do pai com a criança foi descrita pela mãe em alguns momentos (Até ele sair, que ele não saía com o filho, ele tá passando a sair. "Vamos ali com o papai, que não sei o quê". Ele tá chamando assim. Na verdade, você já vê diferença). Percebe-se, aqui, que conforme a criança foi apresentando feedback comunicativo para o pai, isso despertou no responsável o desejo de ter o filho junto para realizar trocas dialógicas, para compartilhar momentos com o menor.

O envolvimento dos pais é capaz de promover o aprendizado da linguagem infantil e enriquecer o relacionamento entre pais e filhos; o que ocorre como uma consequência natural do aumento da sensibilidade dos pais para as necessidades, interesses e esforços comunicativos do infante ${ }^{(5)}$.

Wiethan, Souza e Klinger ${ }^{(15)}$ associam as mudanças na interação entre mães e filhos ao fato de o trabalho grupal em contextos comunitários realçar as potencialidades do grupo como um incentivo à transformação e ferramenta de mudança individual. Tal experiência pode modificar o exercício da função materna e do papel paterno (esse de forma indireta), considerando o efeito familiar dos aspectos trabalhados no grupo.

\section{CONCLUSÃO}

Quando o usuário busca o serviço de saúde, espera ser acolhido e, minimamente, atendido em sua demanda. A proposta do grupo terapêutico como ferramenta de intervenção junto à família utiliza-se do conceito de acolhimento e tem como objetivo responder de forma ética e resolutiva à demanda apresentada pelos usuários, considerando as possibilidades de assistência do serviço público.

Como produto da intervenção grupal com as mães de crianças com alterações de linguagem, na qual es- sas foram acolhidas pela terapeuta e pelo próprio grupo, observaram-se mudanças comportamentais na díade familiar/criança, as quais se deram por efeito de um novo cenário histórico-cultural construído pelo par adulto-criança, um novo modo de acolhimento dos filhos pelas mães.

Sobre tais mudanças, uma das primeiras características observadas no discurso materno para referenciá-las foi o uso do tempo verbal presente ressaltado com os advérbios de tempo (agora, hoje, já). Nos relatos das mães, também aparece a percepção das mesmas sobre a relação existente entre a intervenção do adulto como parceiro da criança na brincadeira e o desenvolvimento linguístico infantil. O entendimento desse encadeamento de ações pode ter dois diferentes desdobramentos. Um deles corresponde ao contexto inicial, em que não há reconhecimento da importância da participação do adulto na brincadeira e o consequente subdesenvolvimento de linguagem. $\mathrm{O}$ outro, a posteriori, refere-se ao maior engajamento lúdico do adulto e, finalmente, ao desenvolvimento linguístico satisfatório. Esse efeito estreita-se com o engajamento de outros interlocutores na interação social com a criança.

Nota-se que o trabalho grupal provocou nas mães uma mudança de olhar, passando-se de uma visão microdimensional para uma visão macrodimensional. Antes, elas "olhavam" para a parte - a fala ou a ausência dela; agora, são capazes de visualizar o todo - o desenvolvimento infantil. Essa nova perspectiva foi possível mediante à compreensão da interseção entre os aspectos de fala/ linguagem, interação e valorização da participação familiar na relação com a criança.

Considerando como resultados desse grupo terapêutico as mudanças ocorridas na relação familiar-criança e o desenvolvimento da linguagem 
infantil, pode-se caracterizar como viável e efetiva a abordagem do SUS com as mães de crianças com alterações de linguagem, principalmente quando se vê oportunidades de oferecer assistência às crianças menores de 3 anos, mesmo que sob abordagem indireta, e de melhorar a dinâmica familiar. Portanto, percebe-se seu potencial de aplicabilidade em outros serviços da rede de assistência, de forma a acolher inúmeras famílias da população brasileira. Apesar de o grupo ter a participação de mães apenas, não se deve perder de vista o objetivo de comprometer, em novas pesquisas, não só a figura materna, mais também do grupo social de origem da criança - a família.

Vale frisar que não se trata de um grupo de orientação. O grupo de familiares com finalidade terapêutica possui uma proposta mais ampla: ser um campo fértil para mudanças no comportamento social de cada indivíduo-membro conforme haja a compreensão e a ressignificação das dificuldades do outro e de si mesmo ${ }^{(8)}$.
Conforme Santos e Montilha ${ }^{(20)}$, as vivências e sentimentos compartilhados entre os membros do grupo, conduzidos pelos mediadores, auxiliam na incorporação de mudanças de comportamentos familiares, beneficiando os indivíduos com alteração de linguagem.

Frente ao exposto, o estudo é relevante à medida que se trata de uma proposta transdisciplinar em Saúde Coletiva, posicionando o fonoaudiólogo como mediador do grupo terapêutico. -

\section{REFERÊNCIAS}

1. Ministério da Saúde, Secretaria de Atenção à Saúde, Núcleo Técnico da Política Nacional de Humanização (BR). Acolhimento nas práticas de produção de saúde. Série B. Textos Básicos de Saúde. $2^{a}$ ed. Brasília: Editora do Ministério da Saúde, 2010. 44p.

2. Acosta VM, Moreno A, Ramos V, Quintana A, Espino O. Avaliação da linguagem: teoria e prática do processo de avaliação do comportamento linguístico infantil. São Paulo: Santos; 2003.

3. Mousinho R. Desenvolvimento da Leitura e Escrita e seus Transtornos. In: Goldfeld M, Org. Fundamentos em Fonoaudiologia - Linguagem. 2a ed. Rio de Janeiro: Guanabara Koogan; 2003. p. $145-154$.

4. Laplane ALF, Batista CG, Botega MBS. Grupo de avaliação e prevenção de alterações de linguagem. In: Santana AP, Berberian AP, Guarinello AC, Massi G, organizadores. Abordagens grupais em fonoaudiologia: contextos e aplicações. São Paulo: Plexus; 2007. p. 165-187.

5. Machado MLCA. Autismo Infantil: uma abordagem fonoaudiológica dirigida à família [monografia]. Rio de Janeiro: Centro de Especialização em Fonoaudiologia Clínica; 2000.

6. Santos VR. Fonoaudiologia e grupo: construção de um processo terapêutico [dissertação]. São Paulo: Pontifícia Universidade Católica de São Paulo; 1993.

7. Correa MB. Considerações sobre terapia de grupo na clínica fonoaudiológica. In: Lier de Vitto MF, organizador. Fonoaudiologia: no sentido da linguagem. $2^{a}$ ed. São Paulo: Cortez; 1997. p. 39-48.

8. Machado MLCA, Berberian AP, Massi G. A terapêutica grupal na clínica fonoaudiológica voltada à linguagem escrita. In: Santana AP, Berberian AP, Guarinello AC, Massi G, organizadores. Abordagens grupais em fonoaudiologia: contextos e aplicações. São Paulo: Plexus; 2007. p. 58-79.

9. Moreira, MD. A orientação fonoaudiológica a pais e a capacitação da linguagem de seus filhos [dissertação]. Santa Maria (RS): Universidade Federal de Santa Maria; 2007.
10. Vygotsky LS. Pensamento e Linguagem. São Paulo: Martins Fontes; 1991.

11. Vygotsky LS. A formação social da mente: o desenvolvimento dos processos psicológicos superiores. $7^{\text {a }}$ ed. Cole M, John-Steiner V, Scribner S, Souberman E, organizadores. Cipolla Neto J, Barreto LSM, Afeche SC, tradutores. São Paulo: Martins Fontes; 2007.

12. Pepper J, Weitzman E. It takes two to talk: a practical guide for parents of children with language delays. $4 \mathrm{a}$ ed. Canada: The Hanen Centre; 2004.

13. Marcuschi LA. Análise da Conversação. São Paulo: Ática; 2003.

14. Góes MCR. A abordagem microgenética na matriz histórico-cultural: uma perspectiva para o estudo da constituição da subjetividade. Cad CEDES 2000; 20(50):9-25.

15 Wiethan FM, Souza APR, Klinger EF. Abordagem terapêutica grupal com mães de crianças portadoras de distúrbios de linguagem. Rev Soc Bras Fonoaudiol 2010; 15(3):442-451.

16. Vitto MMP, Féres MCLC. Distúrbios da Comunicação Oral em Crianças. Medicina 2005; 38(3/4):229-234.

17. Hage SRV. Avaliando a linguagem na ausência da oralidade: estudos psicolinguísticos. São Paulo: EDUSC; 2001.

18. Russo DAS. Avaliação qualitativa da utilização do grupo terapêutico de familiares no desenvolvimento de crianças com alterações de linguagem [dissertação]. Niterói (RJ): Universidade Federal Fluminense; 2019.

19. Mogford K, Bishop D. Desenvolvimento da linguagem em condições normais. In: _._________-_. Desenvolvimento da linguagem em circunstâncias excepcionais. Rio de Janeiro: Revinter; 2002. p. 1-26.

20. Santos JLFD, Montilha R C I. Grupo de familiares de indivíduos com alteração de linguagem: o processo de elaboração e aplicação das atividades terapêuticas. Rev CEFAC 2016; 18(1):184197. 